\title{
A Humanização na Formação Acadêmica em Saúde: Perspectiva de Egressos de um Projeto de Extensão
}

\author{
The Humanization in the Academic Formation in Health: Perspective of Graduates of an \\ Extension Project
}

\section{Humanización en la Educación Académica en Salud: Perspectiva de los Graduados de un Proyecto de Extensión}

\author{
Ana Carolina de Moraes Silva ${ }^{1}$ \\ Maíra Bonafé Sei \\ Universidade Estadual de Londrina (UEL)
}

\begin{abstract}
Resumo
Um desafio para as instituições de ensino superior é a formação pautada nas políticas de saúde, tendo os projetos de extensão colaborado para suprir essas demandas. Neste trabalho, investigouse a concepção acerca do processo de formação e a humanização em saúde, pela perspectiva de ex-colaboradores de um projeto de extensão multidisciplinar. Trata-se de um estudo qualitativoexploratório, com dados coletados por meio de entrevistas semidirigidas e analisados pela análise de conteúdo categorial. Foram delineadas categorias referentes à formação curricular, autogestão estudantil e aprendizados advindos desta prática. Foram discutidos os currículos e como uma aprendizagem pautada na autonomia, no protagonismo e no lúdico pode desenvolver habilidades singulares e essenciais para o profissional. Percebe-se, ademais, uma mudança nos paradigmas de ensino e atuação em saúde, apontando para a relevância de espaços onde os estudantes possam
\end{abstract} vivenciar processos que contemplem o âmbito político, social e subjetivo do cuidado.

Palavras-chave: relações interprofissionais, ensino, capacitação profissional, humanização da assistência, Sistema Único de Saúde (SUS)

\begin{abstract}
A challenge for higher education institutions is education based on health policies, with extension projects that collaborate to meet those demands. In this work, the conception about the training process and humanization in health was investigated, from the perspective of former collaborators of a multidisciplinary extension project. This is a qualitative-exploratory study, with data collected through semi-directed interviews and analyzed by the categorical content analysis. Categories were outlined regarding curricular training, student self-management and learning derived from this practice. The curricula were discussed and how learning based on autonomy, protagonism, and play can develop unique and essential skills for the professional. In addition, there is a change in the paradigms of teaching and acting in health, pointing to the relevance of spaces where students can experience processes that contemplate the political, social, and subjective scope of care.

Keywords: interprofessional relations, teaching, professional training, humanization of assistance, Brazilian National Health Service

\section{Resumen}

Un desafío para las instituciones de educación superior es la capacitación basada en políticas de salud, como proyectos de extensión, que colaboran para satisfacer estas demandas. En este trabajo, se investigó la concepción sobre el proceso de formación y la humanización en salud, desde la perspectiva de los antiguos colaboradores de un proyecto de extensión multidisciplinar. Este es un estudio cualitativo exploratorio, con datos recopilados a través de entrevistas semidireccionadas y analizados por análisis de contenido categórico. Se describieron las categorías relacionadas con la formación curricular, la autogestión de los estudiantes y el aprendizaje de esta práctica. Se discutieron los planes de estudio y cómo el aprendizaje basado en la autonomía, el protagonismo y el lúdico puede desarrollar habilidades únicas y esenciales para el profesional. Además, hay un cambio en los paradigmas de la enseñanza y la actuación en salud, señalando la relevancia de los espacios donde los estudiantes pueden experimentar procesos que contemplan el alcance político, social y subjetivo de la atención.

Palabras clave: relaciones interprofesionales, enseñanza, capacitación profesional, humanización de la atención, Sistema Único de Salud (SUS)
\end{abstract}

\footnotetext{
${ }^{1}$ Endereço de contato: Rodovia Celso Garcia Cid, PR-445, Km 380, Campus Universitário, Londrina, Paraná. . Telefone: (011) 96596-3850. E-mail: anacarolianams@gmail.com
} 


\section{Introdução}

O ensino superior tem inúmeros documentos que o regulamentam (Corsino \& Sei, 2019), como as Diretrizes Curriculares Nacionais (DCNs), que são orientações padronizadas para a elaboração dos projetos político-pedagógicos (PPP) e dos currículos (Costa, Silva, Lima, \& Ribeiro, 2018). Tais projetos são amplos e refletem acerca das prioridades para a formação, tendo esse caráter político devido aos princípios de cidadania, protagonismo e transformação social (Nóbrega-Therrien, Guerreiro, Moreira, \& Almeida, 2010). Os PPP, desse modo, buscam desenvolver competências e habilidades profissionais, por meio de um processo "interativo-colaborativo", que depende da implicação dos sujeitos, dado o seu caráter coletivo, e integra princípios de reflexão, criatividade e racionalização (Nóbrega-Therrien et al., 2010, p. 681).

O processo de formação dos profissionais da saúde é um desafio para as instituições de ensino superior (Biscarde, Pereira-Santos, \& Silva, 2014). Este desafio se dá a partir da busca pela formação de profissionais que tenham um perfil adequado para a atuação no Sistema Único de Saúde (SUS), o que abrange aspectos de humanização, atuação multiprofissional e atenção integral à saúde (Biscarde et al., 2014). Deste modo, a formação constitui-se como uma das principais dificuldades na implementação das políticas de saúde (Silva \& Silveira, 2011; Klafke, Araújo, \& Cardoso, 2013), como a Política Nacional de Humanização (PNH), devido à falta de sensibilização e preparo para lidar com situações que requerem habilidades além do conhecimento técnico.

A implementação da PNH (Brasil, 2004) propõe que a política deve compor o conteúdo acadêmico na graduação, pós-graduação e na extensão em saúde, vinculado à educação permanente, como um dos eixos da estratégia para difusão e apropriação da política na sociedade. No entanto, Corsino e Sei (2019), a partir de uma análise das grades curriculares de cursos da saúde de universidades paranaenses, perceberam que a temática da humanização é pouco abordada nas disciplinas da graduação. Lanzieri, Claro, Bragança, Montezano \& Silva (2011) também apontam que uma das dificuldades da estruturação curricular na graduação é se assemelhar à prática profissional. As oposições entre teoria-prática, sujeito-objeto e estudo-intervenção, presentes na formação acadêmica, têm ". . . contribuído na perpetuação de processos de formação divorciados dos processos de trabalho, ou seja, da experiência concreta" (Brasil, 2010, p. 24).

A PNH é criada para lidar com essa fragmentação e com a verticalização dos processos de trabalho, como também para integrar as dimensões sociais e subjetivas existentes na atuação (Brasil, 2004). Humanizar, portanto, deve ser entendido como uma construção coletiva, que inclui como protagonistas trabalhadores, gestores e usuários, e a oferta de atendimento de qualidade junto de avanços tecnológicos e acolhimento, propiciando tanto a autonomia e corresponsabilidade dos usuários no cuidado de si quanto dos profissionais na melhora das condições de trabalho (Brasil, 2004).

Para suprir as demandas da formação, há a implementação de projetos de extensão, visto que permitem experiências ampliadas, ultrapassando os processos tradicionais de formação, revelando-se essenciais na educação superior (Biscarde et al., 2014). Enxerga-se que a formação em saúde vai além das habilidades técnicas, possuindo também um compromisso político (Goulart \& Chiari, 2010), tendo as humanidades capacidade para auxiliar em 
uma visão menos fragmentada (Lima, Guzman, De Benedetto, \& Gallian, 2014). Ceccim e Feuerwerker (2004) corroboram com essa noção, apontando para a existência de instituições formadoras com relevância social, o que significa formar sujeitos implicados com as demandas em saúde.

As atividades de extensão, que permitem contato prático com a realidade de trabalho e a sociedade, são previstas em projetos pedagógicos, devido à indissociabilidade do tripé de formação - ensino, pesquisa e extensão. Para Silva, Muhl e Moliani (2015), a inserção da humanização nos currículos é um avanço para a formação, no entanto, não é completamente eficiente, visto que mudanças não se concretizam sem prática e incentivo. Schneider e Vieira (2011) defendem que a abordagem educativa constrói uma determinada visão de mundo que reverbera na atuação profissional e, consequentemente, na sociedade. Com isso, é necessário refletir acerca das concepções que estão sendo reproduzidas na formação em saúde.

Os discentes da área da saúde, por meio de organizações, como ligas acadêmicas e projetos de extensão, têm expressado suas preocupações acerca da formação e da atuação (Paiva, 2013), reconhecendo brechas na formação acadêmica e buscando soluções para o aprendizado. Para Klafke et al. (2013), os estudantes abrigam potencialidades para produção de mudanças no sistema de ensino por serem críticos, inquietos diante das problemáticas e acessíveis a alternativas na condução do processo de ensino e aprendizagem.

Com este intuito, foi criado o projeto "Sensibilizarte: humanizar através da arte", em 2007. O projeto, idealizado por discentes de medicina, visa à humanização dos estudantes, por meio de recursos artísticos, organizados em quatro frentes: Artesanato, Contação de Histórias, Música e Palhaço. O projeto engloba os cursos de Educação Física, Enfermagem, Farmácia, Fisioterapia, Medicina, Odontologia, Psicologia e Serviço Social, caracterizando-se a partir de uma abordagem interdisciplinar e multiprofissional (Corsino \& Santos, 2018).

O projeto, desenvolvido em uma universidade pública do interior do Paraná, tinha inicialmente caráter estritamente voluntário. Em 2014, tornou-se projeto de extensão e as atividades passaram a ser reconhecidas como acadêmicas pela universidade (Corsino \& Santos, 2018). Salienta-se que, desde o início, o Sensibilizarte é coordenado pelos próprios estudantes, colaboradores do projeto, tendo um Estatuto que orienta o seu funcionamento.

As atividades do projeto dividem-se em entradas no hospital e capacitações. Cada frente de atuação tem especificidades na organização dessa dinâmica de trabalho. Entretanto, os estudantes se reúnem semanalmente, ora para realizar dinâmicas que desenvolvam suas habilidades e relações, ora para realizar intervenções com os pacientes, acompanhantes e funcionários no hospital. As entradas ocorrem, majoritariamente, no Hospital Universitário $(\mathrm{HU})$, nas enfermarias feminina, masculina, pediatria, maternidade e nos prontos-socorros e, semestralmente, no Hospital do Coração.

Rosito e Loterio (2012) apontam a arte como ferramenta necessária para o desenvolvimento de sensibilidade, autonomia e humanização. Com base nessa perspectiva, outras propostas de projetos de extensão também buscam promover a humanização, como é o caso do projeto "Boa noite, bom dia HUAP!", da Universidade Federal Fluminense (UFF), que integra estudantes de diferentes cursos e desenvolve competências, como a comunicação, capacidade de cuidado e empatia (Lanzieri et al., 2011). Na Universidade Federal do Paraná (UFPR), Rosevics et al. (2014) apresentam o "ProCura - A arte da vida", projeto de extensão 
que almeja implementar a humanização nas relações profissionais e pessoais dos alunos, baseado em três pilares: relação estudante-paciente, relação estudante-estudante e formação teórico-reflexiva.

No que se refere a este estudo, entende-se que refletir acerca da formação acadêmica dos profissionais de saúde, a partir da participação em um projeto de humanização, possibilita avaliar os impactos desta prática. Reavalia-se, assim, as atividades, para uma formação de profissionais humanizados de acordo com a realidade de suas atividades profissionais, algo que, consequentemente, impacta no atendimento à saúde da população. Também possibilita repensar a formação e suas estratégias, podendo suscitar ideias e propostas similares.

Com o objetivo de compreender a experiência de profissionais a respeito da formação e da Humanização em saúde, estudos apresentaram experiências, a partir de concepções: da fisioterapia, com concluintes do curso acerca da humanização na sua formação (Silva \& Silveira, 2011), como também com estudantes sobre os significados de um projeto de humanização (Schneider \& Vieira, 2011); e da enfermagem e medicina, com discentes em uma disciplina eletiva para a promoção da humanização no contexto da graduação em saúde (Lima et al., 2014). Diante do exposto, neste trabalho optou-se por investigar a concepção acerca do processo de formação e a humanização em saúde, pela perspectiva de ex-colaboradores de um projeto de extensão multidisciplinar.

\section{Método}

Esta pesquisa se caracteriza como empírica, de natureza qualitativa e caráter exploratório (Turato, 2013; Silva \& Silveira, 2011), tendo em vista a investigação subjetiva da concepção de profissionais, ex-colaboradores do projeto de extensão Sensibilizarte, sobre o processo de formação e a humanização em saúde.

\section{Participantes}

Participaram 16 profissionais graduados em cursos da área da saúde, que colaboraram no projeto de extensão "Sensibilizarte: humanizar através da arte". A amostra foi composta de maneira intencional, visto que houve a busca proposital de sujeitos com vivências específicas ao tema investigado (Turato, 2013). Os participantes selecionados faziam parte da frente da Contação de Histórias, tendo sido escolhida a representação de apenas uma única frente do projeto, devido às especificidades de atuação de cada um dos recursos expressivos e o intuito de realizar um estudo aprofundado dentro dessa particularidade.

Os participantes poderiam ser de qualquer um dos cursos que o projeto abrange; dessa forma, a amostra foi composta por representantes de cinco áreas: Psicologia, Medicina, Enfermagem, Fisioterapia e Odontologia. Estabeleceu-se como critério de inclusão um tempo mínimo de um ano de participação no projeto. Não houve critérios acerca do tempo de formado, portanto, a amostra abrange desde um mês até sete anos de formação, conforme exposto na caracterização dos participantes (Tabela 1). Para identificação, foram utilizadas as siglas iniciais dos cursos, a fim de diferenciar a área de formação, seguidas de numeração aleatória para distinção e sigilo das informações. 
Tabela 1

Caracterização dos participantes da pesquisa

\begin{tabular}{|c|c|c|c|c|}
\hline Id. & Sexo & Tempo de Formado & Tempo de Participação & Foi Coordenador? \\
\hline PSI1 & $\mathrm{F}$ & 4 anos & 2 anos & \\
\hline $\mathrm{PSI} 2$ & M & 1 mês & 2 anos & Sim \\
\hline PSI3 & $\mathrm{F}$ & 1 ano & 4 anos & \\
\hline PSI4 & $\mathrm{F}$ & 1 mês & 3 anos & Sim \\
\hline PSI5 & $\mathrm{F}$ & 2 meses & 4 anos & Sim, durante 3 anos \\
\hline PSI6 & $\mathrm{F}$ & 1 ano e 2 meses & 3 anos & \\
\hline PSI7 & $\mathrm{F}$ & 5 anos & 5 anos & \\
\hline ENF1 & $\mathrm{F}$ & 6 meses & 3 anos & \\
\hline ENF2 & $\mathrm{F}$ & 2 anos & 2 anos & \\
\hline ENF3 & $M$ & 7 anos & 6 anos & \\
\hline ODONTO & $\mathrm{F}$ & 1 ano e seis meses & 1 ano & \\
\hline MED1 & $\mathrm{F}$ & 6 meses & 3 anos & Sim \\
\hline MED2 & M & 3 anos & 1 ano & \\
\hline MED3 & $\mathrm{F}$ & 5 anos & 6 anos & Sim \\
\hline FISIO1 & $\mathrm{F}$ & 3 anos & 5 anos & Sim \\
\hline FISIO2 & $\mathrm{F}$ & 4 anos & 3 anos & $\operatorname{Sim}$ \\
\hline
\end{tabular}

\section{Procedimentos}

Inicialmente, realizou-se um levantamento dos colaboradores da Contação de Histórias junto à coordenação do projeto. A partir disso, foram descartados aqueles que não se enquadravam nos critérios de inclusão, totalizando 24 possíveis participantes. Houve tentativa de contato com todos esses sujeitos; dessa maneira, o fechamento da amostra se deu por meio do critério de exaustão, visto que foram entrevistados todos os participantes que puderam ser contatados e que aceitaram participar, voluntariamente, desta pesquisa (Fontanella, Ricas, \& Turato, 2008).

Após o aceite, as entrevistas foram realizadas, gravadas e transcritas na íntegra, sendo em seguida organizadas em arquivos individuais. A coleta se deu de forma individual, em um momento único, não sendo delimitado tempo de duração, variando conforme a individualidade do participante. Todos os participantes assinaram o Termo de Consentimento Livre e Esclarecido (TCLE), sendo este estudo aprovado pelo Comitê de Ética em Pesquisa com Seres Humanos, CAAE 50271515.7.0000.5231, por meio do parecer 1.316.565.

Para a coleta de dados, foram realizadas entrevistas semidirigidas, a partir de um roteiro disparador previamente elaborado. O roteiro continha questões acerca da motivação para ingressar no projeto, das atividades realizadas e da percepção acerca das experiências vivenciadas. O participante era solicitado a discorrer acerca da relação multiprofissional entre os colaboradores e a influência da participação na formação profissional, assim como relatar sobre o contato com as temáticas da humanização e da utilização de recursos expressivos na graduação.

As entrevistas foram submetidas à análise de conteúdo categorial (Bardin, 2011). O material foi lido na íntegra diversas vezes e foram sendo marcados trechos relevantes, as unidades que seriam analisadas, tendo em vista o objetivo desta pesquisa. A partir dessa codificação, 
foram realizados agrupamentos, formando as categorias. A estruturação do instrumento e a análise dos dados a posteriori corroboram com o caráter exploratório desta temática investigada (Fontanella et al., 2008).

As categorias serão ilustradas a partir de trechos dos depoimentos coletados. Os dados são apresentados de forma similar às metodologias dos estudos de Silva e Silveira (2011), que investigaram a humanização e a formação do profissional em fisioterapia, com concluintes do curso, e de Schneider e Vieira (2011), que também discorreram acerca de uma proposta de educação em saúde. Desse modo, configurou-se, por fim, três categorias de análise: 1) Os cursos da saúde e a formação acadêmica curricular obrigatória; 2) Coordenação e autogestão: engajamento dos participantes; e 3) A experiência e os aprendizados singulares do projeto.

\section{Resultados e Discussão}

\section{Os Cursos da Saúde e a Formação Acadêmica Curricular Obrigatória}

Cada um dos cursos da saúde tem uma Diretriz Curricular Nacional (DCN), que visa a uma formação qualificada, atendendo aos princípios do SUS (Costa et al., 2018). Essa diretriz abrange orientações para a formulação pedagógica, apontando para o desenvolvimento de currículos inovadores, que superem as práticas fragmentadas, formando profissionais com ideais de transformação e criticidade.

Apesar disso, percebe-se que o modelo de atenção à saúde, assim como a formação profissional, ainda está fortemente pautado no pensamento biomédico (Goulart \& Chiari, 2010). Neste trabalho, os participantes foram questionados acerca da presença de conteúdos de humanização na graduação. Algo em comum aos discursos foi o aspecto tecnicista:

Porque eles aprendem protocolos. Eles não, a gente né, a gente aprende formas de fazer, a gente aprende caminhos certinhos, e tem que ser daquela maneira e você incluir a Humanização nisso, é o difícil. (FISIO1, comunicação pessoal, 17 de maio de 2018).

A gente é muito receita do bolo .. . Não existe essa questão de lidar, de como é que fala, da informalidade, é sempre muito formal, sempre muito protocolo, a gente não tem isso. A gente adquire, foi no Sensibilizarte mesmo que você vai adquirir isso. (ENF3, comunicação pessoal, 30 de maio de 2018).

Hoje em dia a faculdade ensina técnica, mas não ensina humanização mais, né. (MED3, comunicação pessoal, 4 de maio de 2018).

Na clínica da odontologia a gente não tem tempo para ter esse contato com o paciente, de perguntar, geralmente é primeira consulta só e depois é batidão. A gente tem que ter mão, e eles batem muito em cima disso, técnica, técnica, técnica. (ODONTO, comunicação pessoal, 10 de maio de 2018).

Nota-se que os profissionais, com exceção da psicologia, relataram uma aprendizagem formal, que não abria espaço para um pensar criativo e "para além" dos procedimentos. Lima et al. (2014) encontraram resultados similares, que apontaram para a racionalização exigida no ensino. Os autores refletem que os discentes não aprendem recursos essenciais para o cuidado ao serem meros reprodutores de conhecimento. Metodologias 
substancialmente técnicas não suscitam a reflexão e criticidade (Oliveira \& Almeida, 2015), não atingindo, dessa forma, o caráter inovador desejado no ensino curricular obrigatório (Costa et al., 2018).

A contínua insistência quanto à técnica expõe a noção de perfectibilidade no manejo e de que o profissional é capaz de solucionar todas as problemáticas a partir disso. Este pensamento equivocado afasta o sujeito de sua humanidade (Lima et al., 2014), causando tensões e estresse a partir da perspectiva de que não se pode falhar. Diante disso, destaca-se que "o sucesso de um bom profissional não depende apenas de sua competência profissional, e sim de outros fatores que podem ser transmitidos a partir da extensão universitária" (Oliveira \& Almeida, 2015, p. 23).

Tais fatores abrangem questões sociais, humanistas, solidárias e os direitos humanos. Não se exclui a importância incontestável do saber técnico-científico, no entanto, coloca-se que não é o suficiente para uma prática efetiva em saúde (Biscarde et al., 2014), devido ao caráter subjetivo do paciente, objeto do trabalho, que não pode ser minimizado (Silva et al., 2015).

O fazer essencialmente técnico distancia profissional e paciente (Lima et al., 2014); desse modo, o Sensibilizarte busca atuar a partir de princípios humanísticos, com recursos artísticos que propiciam a aproximação entre esses sujeitos. Rosito e Loterio (2012) refletem acerca da possibilidade de os profissionais atuarem e enfrentarem os desafios da prática, a partir de uma educação libertadora, pautada na autonomia e humanização. As metodologias de ensino devem suscitar o pensamento crítico e a autonomia do estudante, atuando de acordo com os pressupostos das políticas de saúde (Brasil, 2004).

Analisando a perspectiva dos participantes sobre o currículo a partir de cada área profissional, verificou-se que os profissionais da psicologia não tiveram a oferta de disciplinas acerca da humanização ou das Políticas Públicas de Saúde, como ilustrado no seguinte relato:

A gente tem uma perspectiva totalmente diferente do que era ensinado na graduação, principalmente para mim que não tive o módulo de saúde. Então, o que eu conheci de saúde durante a graduação, além de busca ativa/pessoal, foi no Sensibilizarte, com os Simpósios, as capacitações. (PSI6, comunicação pessoal, 23 de abril de 2018).

Os psicólogos apontaram para a importância do projeto no ensino, visto a falta de conteúdos curriculares acerca desta temática, como também reconheceram sua relevância e necessidade na formação profissional, para integralidade do cuidado e a inserção da psicologia no campo da saúde. Em uma pesquisa realizada com psicólogas acerca da experiência no Sensibilizarte, foi constatada também a necessidade de buscar uma formação complementar, tendo o projeto se configurado como uma experiência inicial (Oliveira, Murata, \& Sei, 2015).

Os participantes dos cursos de medicina e fisioterapia afirmaram que não havia nenhuma abordagem direta, mas que existiam alguns comentários em certas disciplinas que tratavam um pouco da relação com o paciente e aspectos da humanização, conforme indicado nas seguintes falas:

Propriamente humanização, não. Então assim, é por trás dos panos . . . talvez por não preparo dos profissionais que estejam ali, mas eu acho que diretamente trabalhar Humanização, não foi trabalhado. O que foi trabalhado foram métodos que têm base a 
Humanização para lidar com o paciente, mas questão de bom senso também. (FISIO1, comunicação pessoal, 17 de maio de 2018).

Tinha essa tentativa entendeu . . . a gente tinha prova, a gente tinha aulas práticas de humanização, de comunicação médico-paciente. (MED3, comunicação pessoal, 4 de maio, 2018).

A tentativa de ensinar humanização, como pontuado pela profissional da medicina, existe nos currículos do curso, com a inserção de conteúdos de humanização nas matérias obrigatórias (Silva et al., 2015). No entanto, percebe-se que este tema não está consolidado no processo de ensino. Na fisioterapia, Silva e Silveira (2011) também não encontram nenhuma disciplina específica, refletindo que, além desta especificidade, seria essencial que a humanização estivesse presente atravessando todo o processo de ensino-aprendizagem.

Outro apontamento, ilustrado pelo discurso da fisioterapeuta, é a formação dos professores. Esses profissionais, muitas vezes, também não tiveram essa temática abordada em sua formação, precisando, deste modo, adquirir propriedade a fim de repensar as melhores formas de trabalhar os conceitos com os discentes (Goulart \& Chiari, 2010). Silva et al. (2015) conjecturam que a simples alteração das ementas não significa que o conteúdo será acolhido pelo profissional em sala de aula. Já no âmbito da enfermagem e odontologia, foi pontuado que há o ensino de humanização, mas que ainda faltam conteúdos, como exposto pelos participantes:

Geralmente elas abordam o tema humanização, mas não como o Sensi proporciona, é só uma coisa assim, ah, tem que ter humanização, não discorre sobre o tema. (ENF1, comunicação pessoal, 15 de abril de 2018).

Humanização as pessoas confundem um pouco com educação, ser cordial. (ENF3, comunicação pessoal, 30 de maio de 2018).

Foi, a gente tem saúde coletiva, e sempre era abordado ... e, durante a graduação, você não tem um negócio tipo corpo a corpo sabe. Então foi um dos motivos que eu procurei o Sensibilizarte, porque eu queria ter esse contato. (ODONTO, comunicação pessoal, 10 de maio de 2018).

Percebe-se nos relatos dos participantes que há uma abordagem superficial da temática, assim como uma certa confusão ao se tratar do conceito de Humanização. Dessa forma, as diretrizes de Humanização, pautadas na PNH (Brasil, 2004), não são reconhecidas pelos estudantes dentro do currículo obrigatório de seus respectivos cursos de formação. Entende-se que há limitações nas grades curriculares, visto não ser possivvel abranger profundamente todos os conteúdos, fazendo-se uso da extensão e da pesquisa para complementar a formação. No entanto, percebe-se que os estudantes não sentem que possuem uma base mínima da temática de Humanização, sendo essa necessária para o desenvolvimento teórico-prático, mesmo que por outras vias de formação.

Nota-se que, apesar de a PNH existir há aproximadamente quinze anos, a partir de cartilhas de formação e ensino, ainda não há sua implementação adequada no projeto político-pedagógico dos cursos da saúde (Corsino \& Sei, 2019). Costa et al. (2018) também concluíram que as DCNs, em sua maioria, tinham aspectos tradicionais de ensino, não demonstrando orientações claras para a instauração de mudanças inovadoras. Desse modo, 
percebe-se que tanto as Instituições de Ensino Superior, na elaboração dos PPP e dos currículos, quanto as DCNs não incentivam a inclusão adequada da Humanização nos cursos de saúde, o que demonstra que essa temática acaba não sendo vista como essencial e um importante elemento dos currículos de saúde.

\section{Coordenação e Autogestão: Engajamento dos Participantes}

A coordenação do Sensibilizarte é feita pelos próprios alunos, a partir de uma autogestão, tendo o professor coordenador uma função pontual de orientação e resolução de questões burocráticas junto à universidade. Assim como nas ligas acadêmicas (Paiva, 2013), os estudantes idealizam e executam as atividades, sendo os protagonistas desde a criação, até a execução do projeto. Ressalta-se que protagonismo e autonomia não devem ser compreendidos como independência ou autossuficiência (Brasil, 2010), mas sim como a capacidade de gerir em conjunto, a partir da colaboração crítica e individual de todos que componham o coletivo.

Busca-se estabelecer no projeto uma relação horizontal, em que cada um dos participantes está incluído em todos os processos (Brasil, 2004), como proposto na diretriz da PNH de cogestão. A cogestão, como modo de organização da saúde, faz com que os envolvidos se coloquem ativamente nas situações, visando ao coletivo à medida que o planejamento se dá de modo horizontal, não hierarquizado e compartilhado (Klafke et al., 2013). Desse modo, os alunos tornam-se "referência" (sic), como colocado pela profissional da psicologia:

Você vai se aprimorando, coisas que às vezes você não conseguia observar antes, você passa a observar com mais facilidade, ... você acaba virando referência depois de um tempo para pessoas novas dentro do projeto. (PSI3, comunicação pessoal, 27 de abril de 2018).

Entende-se que há um funcionamento colaborativo, visto que a posição de coordenador não funciona de modo hierárquico, mas como um modo de organização para o funcionamento do projeto. Desse modo, percebe-se que no Sensibilizarte havia um sentimento de confiança para apontar quando as atividades não estavam ocorrendo como esperado, utilizando-se de feedbacks e momentos de reflexão sobre o andamento do grupo, um espaço para todos poderem opinar, como representado nos relatos das participantes da psicologia:

Desde a época que eu entrei, existiu uma organização melhor, essa organização foi se perdendo, porque, como você sabe, ela é feita pelos próprios alunos, os alunos têm suas questões pessoais e suas atividades e às vezes ficava um pouco solto, ... mas a gente sempre foi muito unido, e acabava que isso era discutido no próprio grupo. (PSI6, comunicação pessoal, 23 de abril de 2018).

Já ajudei a preparar capacitação, já participei, às vezes a gente separava um dia para fazer um feedback com todo mundo, para ver como é que estava. (PSI3, comunicação pessoal, 27 de abril de 2018).

Percebe-se, conforme pontuado pelas participantes, que os discentes se mostram preocupados com as sugestões de todos os envolvidos no projeto, visando a um constante aprimoramento deste espaço de aprendizagem. As DCNs têm como objetivo garantir a formação 
de profissionais autônomos, que saibam "aprender a aprender", sendo que as diretrizes de todos os cursos presentes neste trabalho apontam para educação permanente em saúde enquanto uma competência geral necessária (Brasil, 2001). Para Nóbrega-Therrien et al. (2010), o processo educacional deve ser crítico-reflexivo, estimulando a autonomia no pensar e transformando os discentes em protagonistas ativos de mudanças no cenário da saúde.

O protagonismo do discente propõe a quebra da relação de dependência, o que pressupõe "um reposicionamento na relação de poder" (Brasil, 2010). Torna-se, portanto, uma relação que se dá "entre" indivíduos e não um sobre o outro. Esse paralelo existe tanto na relação de cuidado médico-paciente, pautado na $\mathrm{PNH}$, quanto na educação, ilustrado na dependência entre professor-aluno, o que, certas vezes, traz a noção de assistencialismo, consolidando a ideia de que as resoluções dependem somente de ações alheias ao indivíduo (Rosito \& Loterio, 2012). A inovação pedagógica consiste na aprendizagem crítico-reflexiva, em que o professor atua como facilitador, e os discentes, de modo ativo (Costa et al., 2018). Ceccim e Feuerwerker (2004) apontam que deve ser incentivado o protagonismo estudantil, por possibilitar inovações no ensino e no sentido dos serviços de saúde.

No entanto, tal movimento em busca de uma conduta protagonista e autônoma dos futuros profissionais é uma mudança na estrutura da saúde (Brasil, 2010) e da educação, no modo das pessoas atuarem, educarem e serem educadas, configurando-se, portanto, como uma tarefa difícil, visto a necessidade de desprender dos modelos aprendidos (Klafke et al., 2013).

Verifica-se a relevância de superar os modelos de aprendizagem tradicionais, pautados no conhecimento biomédico. Schneider e Vieira (2011) consideram que espaços que promovam iniciativas e discussões do tema da humanização, como o Sensibilizarte, podem atuar para desmistificar essa hegemonia vigente. Reflete-se acerca da necessidade de mudanças de paradigma tanto no cenário da atenção e do cuidado quanto nos processos educacionais em saúde.

A partir da corresponsabilização pelo projeto, os estudantes se apropriam deste espaço, criando um sentimento de pertencimento e vinculação. Nota-se tal fato tanto por meio da emoção ao relatar quanto pelo cuidado e pela noção de construção presente nos discursos:

A princípio, ele começou muito, a gente, o Sensibilizarte foi se descobrindo, e os sensibilizartistas se descobrindo junto com Sensibilizarte, entendeu? A gente foi crescendo junto, a gente foi ganhando formas juntos. (ENF3, comunicação pessoal, 30 de maio de 2018).

Foi um crescimento, muitas trocas ali, e daí a gente foi desenvolvendo o projeto, acrescentando coisas, tipo, eu respeito a sua diferença aqui, você respeita a minha aqui, e daí a gente foi, foi crescendo. (PSI7, comunicação pessoal, 21 de maio de 2018).

Hoje o projeto, depois da gente, o projeto andou com suas próprias pernas, ele não precisa mais de uma pessoa comandando isso, é todo mundo, ao mesmo tempo e fazendo tudo e vai dar certo. (MED3, comunicação pessoal, 4 de maio de 2018).

Percebe-se nos relatos uma noção de continuidade, de que o projeto continuaria independentemente da saída de um membro ou da mudança de um coordenador. A participante de medicina coloca a noção de autogestão explicitamente, pontuando que não é necessário alguém "no comando" (sic), pois o projeto funciona a partir da coletividade 
instituída. Da mesma maneira que a participante da psicologia aponta para a construção coletiva que resulta no que o Sensibilizarte representa, complementada pelo relato do profissional da enfermagem, que expõe o crescimento mútuo, tanto do projeto quanto de seus participantes.

Essa interação entre estudantes, como pontuado por Machado, Miranda e Sei (2019), coloca todos os colaboradores na mesma condição de aprendizes, o que facilita reconhecer a relevância do outro neste processo de construção. Desta forma, verifica-se que este modo de o projeto funcionar parece contribuir para o engajamento dos participantes, a partir da responsabilização pela construção e continuidade da ação.

Logo, esse modelo de aprendizagem gera impactos no desenvolvimento do projeto, que cresce não só com a entrada de novos colaboradores, mas também por meio do engajamento desses participantes em executar novas ideias, estender a ação para outros contextos e melhorar a prática realizada. Não somente, são notadas consequências pessoais na formação dos profissionais que participaram desta pesquisa, que passaram a reproduzir as características do projeto - participação ativa, autonomia, protagonismo e engajamento - em outros contextos, configurando estes como alguns dos aprendizados singulares do projeto.

\section{A Experiência e os Aprendizado Singulares do Projeto}

O Sensibilizarte atua no contexto hospitalar, propiciando encontros intermediados por recursos artísticos-expressivos. Esses recursos auxiliam na atenção do cuidado, na sensibilidade e estimulam a expressão de afetos e empatia (Rosevics et al., 2014). Essa vivência ressoa emocionalmente nos participantes, e o projeto estimula que seus colaboradores experienciem essa vulnerabilidade emocional de forma que seja benéfica para o trabalho, colaborando na construção da relação com o paciente e com o grupo, conforme apresentado:

... o Sensibilizarte ensinava justamente sobre ficar vulnerável e eu tinha para mim que ficar vulnerável era uma coisa horrível e o projeto foi tirando essa ideia e foi mostrando que não, que estar vulnerável era permitir essa relação com o outro. (PSI6, comunicação pessoal, 23 de abril de 2018).

Você aprende a ouvir, a escutar, muito comum da psicologia, mas não comum nos outros cursos ... eu era uma pessoa bem tímida, nos meus primeiros estágios, eu só chegava lá e falava o que eu tinha que falar "olha eu tô fazendo a medicação", pronto. E agora eu desenvolvi conversar mais com as pessoas e pedir permissão para fazer as coisas, enquanto eu vou conversando, eu vou fazendo, vou explicando. (ENF1, comunicação pessoal, 15 de abril de 2018).

Percebe-se que o projeto trabalha no sentido de ampliação do cuidado, em que, para o exercício desse cuidado integral, é necessário desenvolver técnicas de relação, de escuta tanto do outro como de si mesmo, além do manejo de problemas sociais e subjetivos e da capacidade crítica para repensar as ações automatizadas (Brasil, 2009). No projeto, os discentes entram em contato com as diretrizes da Humanização e do SUS e percebem que, para a prática humanizada, é necessária uma mudança de comportamento (Brasil, 2010), como exposto no comentário da profissional da Enfermagem, que repensou sua atuação enquanto estagiária e passou a atuar de modo diferente. Dessa forma, a fim de conseguir transformar 
a formação e o trabalho em saúde, necessita-se mais do que simples mudanças técnicas, visto que todo esse processo de atenção e cuidado abrange modificações nos processos, relações e, essencialmente, nos sujeitos (Ceccim \& Feuerwerker, 2004).

Para conseguir concretizar essas mudanças pessoais e coletivas, os estudantes vão desenvolvendo habilidades, a partir da relação com o outro e da aproximação com os sentimentos que resultam deste encontro. O exercício de se colocar vulnerável e atento às próprias emoções permite que se formem vínculos, colaborando na compreensão do caso e na atenção ao paciente, a partir do desenvolvimento de empatia - principal elemento da relação equipe-paciente (Rosevics el al., 2014). Essa oportunidade de relação com o paciente, além do procedimento, permite novas formas de cuidado e que os futuros profissionais saibam cuidar além de sua especialidade (Lanzieri et al., 2011), desenvolvendo habilidades para promoção da saúde e não somente técnicas centradas na doença (Paiva, 2013).

As competências e habilidades gerais previstas para os cursos abordados neste estudo são as mesmas, segundo as DCNs. Esperam-se profissionais com características de liderança, comunicação, tomada de decisões, educação permanente, atenção integral à saúde e administração e gerenciamento (Brasil, 2001). Não somente, busca-se um perfil que seja crítico, reflexivo, generalista e humanista. Percebe, a partir dos relatos, que os participantes do Sensibilizarte puderam desenvolver tais características essenciais:

Eu acho que é o profissional mais completo, mais embasado, mais empoderado. Então você usa suas técnicas de formação acadêmica, mas junto de uma empatia que não existia antes, então você consegue ver esse paciente e se colocar no lugar nele. (FISIO1, comunicação pessoal, 17 de maio de 2018).

Acho que possibilita bastante as pessoas a desenvolver habilidades, saber lidar com outras pessoas, não só dentro do hospital, mas na vida pessoal mesmo. E a conseguir pensar além, assim, no sentido da gente ter que improvisar, . . a gente tem que saber conversar com o paciente, saber, principalmente, ouvir o que ele tem a dizer. (ENF1, comunicação pessoal, 15 de abril de 2018).

Foi bem legal também desenvolver essa parte de ser um coordenador, de ser responsável por levar dinâmicas, . . . entraram novos voluntários, ai eu tinha que ajudar a capacitar essas pessoas, então, foi uma responsabilidade grande. (PSI2, comunicação pessoal, 11 de abril de 2018).

Nota-se, conforme apontado pelos ex-colaboradores nas entrevistas, que o projeto desenvolve características como: comunicação, saber ouvir, empatia, autoconfiança, autoconhecimento, improviso, imaginação, responsabilidade, relacionamento interpessoal, liderança, capacidade de ensinar, organização e enfrentamento de dificuldades e medos. Estes aprendizados também foram relatados em outras pesquisas, por meio de atividades lúdicas (Lanzieri et al., 2011), contadores de história (Silva, 2016), contadores e palhaços (Rosevics et al., 2014), ligas acadêmicas (Paiva, 2013) e em outros estudos do Sensibilizarte (Machado et al., 2019; Oliveira et al., 2015).

Para Rosevics et al. (2014), a aprendizagem se dá tanto na relação com o paciente quanto por meio dos imprevistos presentes no cotidiano. Além do mais, a relação com a arte e com o processo de autoformação discente colabora na construção e no reconhecimento de sua 
própria identidade. O discente passa a ser mais consciente de suas escolhas, construindo a noção de ser profissional (Rosito \& Loterio, 2012). Não somente, percebe-se que a extensão e o contar histórias tem grande impacto na formação do sujeito, colaborando para a construção de indivíduos éticos, críticos e comprometidos com a promoção de saúde (Paiva, 2013).

Silva (2016) aponta que participar de um projeto no qual os estudantes têm autonomia de decisão permite com que eles desenvolvam competências de iniciativa, organização, identidade, autoconfiança, responsabilidade, superação de desafios e disciplina. Na descrição da competência de liderança presente nas DCNs, o profissional deve ser capaz de assumir a posição de líder, no trabalho em equipe multiprofissional, o que envolve características como empatia, responsabilidade, tomada de decisões, comprometimento e comunicação acessível e efetiva (Brasil, 2001). Por meio da autogestão discente do Sensibilizarte, os participantes podem, assim, experienciar situações que os auxiliem no desenvolvimento dessas características.

Dessa forma, percebe-se que há diversos aprendizados possíveis decorrentes da experiência no Sensibilizarte. Estes, entretanto, podem ocorrer porque dependem do engajamento e do envolvimento de cada sujeito em sua própria aprendizagem. Com isso, compreende-se que o projeto se configura como um espaço potencial para o desenvolvimento de características essenciais ao futuro profissional da saúde.

\section{Considerações Finais}

Por meio desta pesquisa, foi possível analisar o processo de formação em saúde, a partir do viés de profissionais que participaram de um projeto de humanização. Percebe-se que os participantes apontam para um ensino tecnicista e, diante das limitações daquilo que pode ser acolhido pela grade curricular, os projetos de extensão se constituem como uma alternativa para a aprendizagem. Entende-se que o método de autogestão permite maior apropriação do conteúdo, visto que esse é vivenciado e não apenas transmitido de forma teórica. Os alunos experienciam os princípios da PNH na prática, na relação com os demais colaboradores do projeto, no contato com o paciente, na organização das atividades e ao serem protagonistas do próprio processo de aprendizagem. O projeto abrange a transversalidade da humanização, diante do posicionamento autônomo, protagonista e ao suscitar o modelo de trabalho participativo em equipe, fundamentais ao profissional da saúde.

Compreende-se que há uma vinculação dos participantes com a proposta do projeto. $\mathrm{O}$ modo de gerenciamento autônomo depende que os discentes se engajem e que construam não só as atividades, mas a sua própria formação. O reflexo disso é o desenvolvimento de habilidades e competências, que são relatados como benefícios, e superação de dificuldades e desafios pessoais. A apropriação do trabalho realizado faz com que os participantes saibam como aprender e se tornem ativos neste processo contínuo de formação, a partir de uma postura responsável e comprometida.

Mudam-se os paradigmas em relação às metodologias de ensino e ao modo de atuação do profissional da saúde. Busca-se não somente o uso de tecnologias e procedimentos, mas um cuidado humano e sensível. Desse modo, é imprescindível integrar a formação generalista e a humanista, visando formar profissionais que contemplem o âmbito político, social e cidadão do cuidado. Precisa-se de espaços para que os discentes possam contextualizar os conhecimentos aprendidos e experienciar esses novos modos de formação. 
Percebe-se que a vivência por meio do Sensibilizarte possibilita um contato prático e diferente dos conteúdos obrigatórios da graduação. O estudante, por meio de recursos artístico-expressivos, como a Contação de Histórias, relaciona-se com o paciente, não somente como um profissional, mas como outro indivíduo. Incentiva-se, portanto, a qualificação do profissional da saúde, preparado para atuar de modo humanizado na realidade dos serviços.

Por fim, quanto aos limites desta pesquisa, entende-se que eles se centram no fato de abordar apenas uma das frentes de atuação do projeto, a Contação de Histórias. Desse modo, propõe-se a relevância de ampliar a investigação a outras frentes, como também aos indivíduos que exerceram funções de coordenação-geral do projeto. Compreende-se que a autogestão dos estudantes pode colaborar para a formação singular do profissional, por isso, sugerem-se maiores estudos acerca de iniciativas no campo da saúde que se utilizem desse método.

\section{Referências}

Bardin, L. (2011). Análise de Conteúdo. São Paulo: Edições 70.

Biscarde, D. G. S., Pereira-Santos, M., \& Silva, L. B. (2014). Formação em saúde, extensão universitária e Sistema Único de Saúde (SUS): Conexões necessárias entre conhecimento e intervenção centradas na realidade e repercussões no processo formativo. Interface: Comunicação, Saúde e Educação, 18(48), 177-186. doi:https://www.doi. org/10.1590/1807-57622013.0586

Brasil. Ministério da Educação. (2001). Diretrizes Curriculares Nacionais dos Cursos de Graduação em Enfermagem, Medicina e Nutrição. Brasília, DF: Ministério da Educação. Recuperado de http://portal.mec.gov.br/dmdocuments/ces1133.pdf

Brasil. Ministério da Saúde. (2004). HumanizasuS. Política Nacional de Humanização: A Humanização como Eixo Norteador das Práticas de Atenção e Gestão em Todas as Instâncias do SUS (Textos Básicos de Saúde, Série B). Brasília, DF: Ministério da Saúde. Recuperado de http://bvsms.saude.gov.br/bvs/publicacoes/humanizasus_2004.pdf

Brasil. Ministério da Saúde. (2009). Clínica Ampliada e Compartilhada (Textos Básicos de Saúde, Série B). Brasília, DF: Ministério da Saúde. Recuperado de http://bvsms.saude.gov. br/bvs/publicacoes/clinica_ampliada_compartilhada.pdf

Brasil. Ministério da Saúde. (2010). Cadernos HumanizaSUS (Formação e Intervenção, Vol. 1). Brasília, DF: Ministério da Saúde. Recuperado de http://bvsms.saude.gov.br/bvs/ publicacoes/cadernos_humanizaSUS.pdf

Ceccim, R. B., \& Feuerwerker, L. C. M. (2004). Mudança na graduação das profissões de saúde sob o eixo da integralidade. Cadernos de Saúde Pública, 20(5), 1400-1410. doi:https:// www.doi.org/10.1590/S0102-311X2004000500036

Corsino, D. L. M, \& Santos, M. S. (2018). Sensibilizarte: 10 anos existindo e colorindo. In D. L. M Corsino, M. S. Santos, \& M. B. Sei (Orgs.), Sensibilizarte: Decompondo as paredes brancas em cores - um corredor de encontros, histórias, canções, recortes e narizes (1a ed., pp. 37-48). Londrina: Universidade Estadual de Londrina.

Corsino, D. L. M., \& Sei, M. B. (2019). A Humanização nas grades curriculares de cursos da saúde de universidades públicas paranaenses. Revista Psicologia e Saúde, 11(1), 4352. doi:https://www.doi.org/10.20435/pssa.v0i0.579 
Costa, D. A. S., Silva R. F., Lima V. V., \& Ribeiro E. C. O. (2018). Diretrizes curriculares nacionais das profissões da Saúde 2001-2004: Análise à luz das teorias de desenvolvimento curricular. Interface: Comunicação, Saúde, Educação, 22(67), 1183-1195. doi:https:// www.doi.org/10.1590/1807-57622017.0376

Fontanella, B. J. B., Ricas, J., \& Turato, E. R. (2008). Amostragem por saturação em pesquisas qualitativas em saúde: Contribuições teóricas. Cadernos de Saúde Pública, 24(1), 17-27. doi:https://www.doi.org/10.1590/S0102-311X2008000100003

Goulart, B. N. G., \& Chiari, B. M. (2010). Humanização das práticas do profissional de saúde: contribuições para reflexão. Ciência \& Saúde Coletiva, 15(1), 255-268. doi:https://www. doi.org/10.1590/S1413-81232010000100031

Klafke, T. E., Araújo, B. R., \& Cardoso, C. G. (2013). Formação em saúde e protagonismo estudantil: Grupo de estudos e trabalhos em saúde coletiva. Psicologia Ensino \& Formação, 4(1), 3-19. Recuperado de http://pepsic.bvsalud.org/scielo. php?script=sci_arttext\&pid=S2177-20612013000100002\&lng=pt\&tIng=pt

Lanzieri, P. G., Claro, L. B. L., Bragança, F. C. R., Montezano, V. R. S., \& Silva, C. S. (2011). "Boa noite, bom dia HUAP!", uma experiência de humanização na formação de profissionais da área de saúde. Interface: Comunicação, Saúde, Educação, 15(36), 289-298. doi:https:// www.doi.org/10.1590/S1414-32832010005000031

Lima, C. C., Guzman, S. M., De Benedetto, M. A. C., \& Gallian, D. M. C. (2014). Humanidades e humanização em saúde: A literatura como elemento humanizador para graduandos da área da saúde. Interface: Comunicação, Saúde, Educação, 18(48), 139-150. doi:https:// www.doi.org/10.1590/1807-57622013.0708

Machado, I. C., Miranda, F. S., \& Sei, M. B. (2019). O artesanato no projeto Sensibilizarte: Potencialidades na prática da humanização. Interfaces: Revista de Extensão da UFMG, 7(1), 1-591. Recuperado de https://www.ufmg.br/proex/revistainterfaces/index.php/ IREXT/article/view/401/pdf

Nóbrega-Therrien, S. M., Guerreiro, M. G. S., Moreira, T. M. M., \& Almeida, M. I. (2010). Projeto Político Pedagógico: Concepção, construção e avaliação na enfermagem. Revista da Escola de Enfermagem da USP, 44(3), 679-686. doi:https://www.doi.org/10.1590/ S0080-62342010000300018

Oliveira, F. L. B., \& Almeida, J. J., Jr. (2015). Extensão universitária: Contribuições na formação de discentes de Enfermagem. Revista Brasileira de Pesquisa em Saúde, 17(1), 19-24. doi:https://www.doi.org/10.21722/rbps.v17i1.12445

Oliveira, G.C., Murata,M.M.,\&Sei, M.B.(2015).Ainfluência do projetoSensibilizartenaformação dopsicólogo.PsicologiaEnsino\&Formação,6(2),68-86. Recuperadodehttp://pepsic.bvsalud. org/scielo.php?script=sci_arttext\&pid=S217720612015000200006\&lng=pt\&tlng=pt

Paiva, M. L. de F. (2013). Contribuições do pronto sorriso na formação do profissional de saúde (Dissertação de mestrado). Recuperado de https://repositorio.bc.ufg.br/tede/ handle/tede/3890

Rosevics, L., Aguiar, D. A., Borges, C. R., Hasegawa, R., Filho, Yamashita, T. S., Manchak, A. C., \& Azevedo, V. F. (2014). ProCura - A arte da vida: Um projeto pela humanização na saúde. Revista Brasileira de Educação Médica, 38(4), 486-492. doi:https://www.doi.org/10.1590/ S0100-55022014000400010 
Rosito, M. M. B., \& Loterio, M. G. (2012). Formação do Profissional em Saúde: Uma recusa ao esvaziamento da essência do cuidado humano. Educação \& Realidade, 37(1), 125-142. doi:https://www.doi.org/10.1590/2175-623621802

Schneider, L. M., \& Vieira, K. de V. (2011). Saúde e Educação: A humanização do saber através da consciência. Saúde \& Transformação Social, 1(2), 116-123. Recuperado de http:// incubadora.periodicos.ufsc.br/index.php/saudeetransformacao/article/view/519

Silva, C. E. C. (2016). A contação de histórias na extensão universitária e sua contribuição para a formação acadêmica (Dissertação de mestrado). Recuperado de http://tede2. pucrs.br/tede2/handle/tede/6617

Silva, I. D., \& Silveira, M. F. A. (2011). A humanização e a formação do profissional em fisioterapia. Ciência \& Saúde Coletiva, 16(Supl.1), 1535-1546. doi:https://www.doi. org/10.1590/S1413-81232011000700089

Silva, L. A., Muhl, C., \& Moliani, M. M. (2015). Ensino médico e humanização: Análise a partir dos currículos de cursos de medicina. Psicologia Argumento, 33(8), 298-309. doi:https:// www.doi.org/10.7213/psicol.argum.33.080.A006

Turato, E. R. (2013). Tratado da metodologia da pesquisa clínico-qualitativa: Construção teórico-epistemológica, discussão comparada e aplicação nas áreas da saúde e humanas (6a ed.). Petrópolis: Vozes.

\section{Sobre as autoras:}

Ana Carolina de Moraes Silva: Graduada em Psicologia pela Universidade Estadual de Londrina (UEL). Atualmente é psicóloga clínica em consultório particular. E-mail: anacarolianams@gmail.com, Orcid: http://orcid.org/0000-0002-8140-2938

Maíra Bonafé Sei: Doutora e mestre em Psicologia Clínica pela Universidade de São Paulo (USP). Graduada em Psicologia pela USP. Atualmente é professora adjunta do Departamento de Psicologia e Psicanálise da Universidade Estadual de Londrina (UEL). E-mail: mairabonafe@gmail.com, Orcid: http://orcid.org/0000-0003-0693-5029

Recebido em: 16/03/2020

Última revisão: 06/05/2020

Aceite final: 07/05/2020 